\title{
APLICAÇÃO DA APR NA GESTÃO DE RISCO EM UMA PLATAFORMA DE CARREGAMENTO DE COMBUSTÍVEIS
}

\author{
Marcone Freitas dos Reis \\ Centro de Tecnologia da Indústria Química e Têxtil (SENAI CETIQT) \\ Rua Magalhães Castro, 174 - Riachuelo, Rio de Janeiro - RJ, 20961-020 \\ marconefreis11@gmail.com \\ Jorge Freitas de Paula Júnior \\ Centro de Tecnologia da Indústria Química e Têxtil (SENAI CETIQT) \\ Rua Magalhães Castro, 174 - Riachuelo, Rio de Janeiro - RJ, 20961-020 \\ jorgefreitas90@gmail.com \\ Marcos dos Santos \\ Instituto Militar de Engenharia (IME) \\ Praça General Tibúrcio, 80 - Praia Vermelha - Urca, Rio de Janeiro - RJ, 22290-270 \\ marcosdossantos_doutorado_uff@yahoo.com.br \\ Angélica Rodrigues de Lima \\ Centro de Tecnologia da Indústria Química e Têxtil (SENAI CETIQT) \\ Rua Magalhães Castro, 174 - Riachuelo, Rio de Janeiro - RJ, 20961-020 \\ angelicadelima.engprod@gmail.com
}

\section{RESUMO}

A distribuição de combustíveis é fundamental para a garantia do abastecimento nacional, o consumo de combustíveis no Brasil continua aquecido, mesmo com constantes variações no valor de comercialização de alguns produtos. Em virtude desta movimentação, temos impacto positivo no crescimento do PIB (Produto Interno Bruto), no que diz respeito à comercialização destes produtos. Além da comercialização, grandes instituições vêm investindo em infraestrutura devido ao elevado grau de risco e complexidade em suas operações. O presente estudo empreende em técnicas de análise qualitativas e quantitativas de gestão de riscos, baseada em dados operacionais, além de pesquisa de campo, exploratória e descritiva. Através da aplicação da ferramenta APR (Análise Preliminar de Risco), foi possível avaliar o cenário e evidenciar os potenciais riscos, em uma plataforma de carregamento de produtos perigosos. A boa gestão na implementação das recomendações sugeridas contribuirá, principalmente, no aumento do nível de segurança para os colaboradores e prestadores de serviço, na manutenção da operacionalidade de maneira geral. Conforme análise crítica realizada, ficou claro a existência de riscos na plataforma de carregamento de caminhões tanques com os produtos comercializados, o que permitiu propor melhoria na área de atuação estudada.

Palavra-chave: Análise Preliminar de Riscos; Qualitativa; Quantitativa; Plataforma de carregamento; Produtos perigosos. 


\begin{abstract}
Fuel distribution is fundamental to guarantee national consumption, fuel consumption in Brazil, even with variables without market value of products. Emission was excluded and the positive result in GDP growth was not affected by product exports. In addition, large companies have been investing in their risk structures and complexity in their operations. The present study involved qualitative and quantitative risk management analysis techniques, based on operational data, as well as field, exploratory and descriptive research. Preliminary Risk Analyzes, it was possible to verify and present the existence of risks in a platform for loading dangerous products. Risk management is not important as there is no increase in the level of safety for employees and service providers in maintaining overall operability. When this last generation had a risk evolution in the chain of chaining of volumes of commercial products, which propped up to improve the area of study studied.
\end{abstract}

Keywords: Preliminary Risk Analysis; Qualitative; Quantitative; Loading platform; Dangerous products.

\title{
Como Citar:
}

REIS, Marcone Freitas dos; PAULA JUNIOR, Jorge Freitas de; SANTOS, Marcos dos; LIMA, Angélica Rodrigues de. Aplicação da APR na gestão de risco em uma plataforma de carregamento de combustíveis. In: SIMPÓSIO DE PESQUISA OPERACIONAL E LOGÍSTICA DA MARINHA, 19, 2019, Rio de Janeiro, RJ. Anais [...]. Rio de Janeiro: Centro de Análises de Sistemas Navais, 2019.

\section{INTRODUÇÃO}

Em 2016, o mercado nacional movimentou 124 bilhões de litros de combustíveis, o que significa uma queda de 5\% em relação a 2015 e reflete a intensa recessão e o avanço do desemprego no país. Neste cenário de redução de atividade econômica, apesar da redução de $20 \%$ no licenciamento total de automóveis e de $11 \%$ na produção total de veículos leves no Brasil em 2016, o consumo de gasolina cresceu motivado pela alta do etanol hidratado ocorrida a partir de setembro, uma maior oferta do combustível fóssil e por uma janela de oportunidades de importação, permitindo, entre as associadas, um aumento nas vendas. (SINDICOM, 2016)

Diante dessa situação, torna-se necessário priorizar ações e adotar políticas mais contundentes para a prevenção dos fatores de riscos incidentes nos locais de trabalho. Nessa lógica, assume relevada importância mencionar que, no presente mercado globalizado, as relações comerciais bilaterais estão, também, levando em consideração padrões de exigência quanto às condições do meio ambiente natural e do meio ambiente de trabalho onde se produziu o bem ou o serviço. (VOTORANTIM, 2005)

A Análise Preliminar de Riscos (APR) pode ser útil como: ferramenta de revisão geral de segurança em sistemas operacionais, revelando aspectos que às vezes passam despercebidos; em instalações existentes de grandes dimensões; e, quando se quer evitar a utilização de técnicas mais extensas para a priorização de riscos. Esta técnica normalmente é utilizada para análises qualitativas, porém, também pode utilizá-la para identificar cenários de acidentes que serão empregados em estudo de análises quantitativas para a obtenção de índices de risco. (CICCO e FANTAZINNI, 1982)

Neste contexto, considerando a existência de riscos, provenientes das instalações e das atividades perigosas para pessoas, patrimônio e meio ambiente da empresa, o presente 
estudo tem como objetivo realizar a aplicação da ferramenta APR, a fim de identificar os principais riscos existentes na plataforma de carregamento de combustíveis e mensurá-los, gerando assim medidas de prevenção e controle desses riscos.

\section{FUNDAMENTAÇÃO TEÓRICA}

\subsection{REFINO DO PETRÓLEO}

As etapas e processos existentes na indústria petrolífera brasileira são divididos em três fases, são elas: (RIBAS, 2008)

- Upstream: é a atividade de explorar, perfurar e transportar o petróleo cru até as refinarias.

- Midstream: é a fase onde o petróleo é refinado e processado os diversos produtos que serão comercializados.

- Downstream: está diretamente ligado ao processo logístico, entre as refinarias e os consumidores. Nesta fase é feito o bombeio das refinarias, estocagem nas bases secundárias, carregamento nos CT e entrega até os pontos de consumo.

\section{2. ÓRGÃo REGULAMENTADOR}

Toda a fiscalização imposta aos seus operadores de contrato, contratados ou concessionários, tem por finalidade prevenir falhas de segurança em suas operações. Dentro deste contexto, as ações de fiscalização ocorrem de forma auditoriais, onde requisitos não atendidos conforme regulamentos técnicos, especificados pelo órgão regulamentador, implicam em não conformidades, que por sua vez, podem ser classificadas como: crítica, grave, moderada ou leve. (ANP, 2016)

A rotina adotada pelos agentes de fiscalização da Agência Nacional do Petróleo (ANP) é regulamentada pela Resolução ANP $\mathrm{n}^{\circ} 37$ e prevê concessão de prazo para tratamento de não conformidades e eventual lavratura de auto de infração. (ANP, 2016)

\subsection{BASE DE DisTRIBUiçÃo}

Base de distribuição, na definição da ANP, é “a instalação com as facilidades necessárias ao recebimento de derivados de petróleo, ao armazenamento, mistura, embalagem e distribuição, em uma dada área do mercado, de derivados de petróleo”. (ANP, 2016)

\subsubsection{Sistema anti-transbordo}

Todos os caminhões que atualmente exercem atividade de carregamento dentro da base, possui em cada compartimento o sistema anti-transbordo, o qual tem por principal finalidade, reduzir a possibilidade de transbordamento no caminhão durante o carregamento.

Cada caminhão possui um documento chamado aferição, neste documento o Instituto Nacional de Metrologia, Qualidade e Tecnologia (INMETRO), realiza inspeção em cada compartimento do caminhão, com intuito de aferir a capacidade de armazenamento de cada compartimento.

\subsubsection{Tipos de carregamento}

\subsubsection{Carregamento bottom loading}

O sistema de carregamento bottom loading, tem como principal característica o carregamento realizado em nível do solo. Assim que o caminhão entra na plataforma de carregamento, eles são aterrados, e em seguida os braços de carregamento são acoplados diretamente na tubulação do caminhão, localizada nas laterais deles. Esse tipo de 
carregamento tem como vantagem o ganho em produtividade, devido ao simples fato de permitir que o carregamento ocorra em um ou mais compartimentos ao mesmo tempo, de acordo com os produtos e os braços de carregamentos disponíveis, tendo em vista que o operador e o motorista se encontram livre para circulação no local.

\subsubsection{Carregamento top loading}

Por sua vez o sistema de carregamento top loading, tem como principal característica o carregamento na parte superior do tanque do caminhão, onde o motorista deve subir as escadas da ilha de carregamento e acessar o caminhão através da escada pantográfica. Neste processo é imprescindível o uso do cinto trava queda, em seguida o motorista deve ser posicionado junto ao braço de carregamento de maneira que ele se encoste ao fundo do compartimento do caminhão.

\subsection{GERENCIAMENTO DE RISCO}

O processo de gerenciamento de riscos é extremamente importante para prevenir ou mitigar os riscos existentes em um determinado local. Em casos de acidentes que envolvam substâncias perigosas, deve-se seguir uma sequência de medidas, são elas: realizar um levantamento estatístico da área afetada pela substância perigosa; fazer um levantamento das atividades que manipulam as substâncias perigosas; caracterizar as substâncias e suas respectivas quantidades; identificar os riscos e danos que possam ser causados caso o acidente aconteça; implantar medidas para mitigação de acidentes e gerenciar os riscos. (MORAES, 2013)

Para Calixto (2006), as técnicas de análise de risco podem ser caracterizadas como dedutivas ou indutivas. As técnicas dedutivas partem do perigo, aspecto ambiental ou desvio de processo para as causas e consequências com objetivo de propor ações mitigadoras. As técnicas indutivas são o contrário, investigam os possíveis efeitos de um evento desejado partindo de um desvio de processo ou evento indesejado para avaliar as causas e consequências para propor ações mitigadoras.

\subsubsection{Análise preliminar de risco}

Segundo Amorim (2010), faz parte do desenvolvimento da APR à análise dos seguintes elementos:

- Equipamentos perigosos: sistemas de alta pressão e de armazenamento de energia;

- Materiais perigosos: materiais combustíveis, substâncias químicas altamente reativas e substâncias tóxicas;

- Fatores externos: vibração, temperaturas extremas, descargas eletrostáticas e umidade;

- Procedimentos: procedimentos de operação, teste, manutenção e parada, comissionamento e emergência;

- Layout da instalação: disposição dos equipamentos de controle e dos equipamentos de proteção contra acidentes;

- Elementos de apoio à instalação: armazenamento, equipamentos de teste, treinamento e utilidades;

- Equipamentos/Sistemas de segurança: sistemas de atenuação e redundância, extintores de incêndio e equipamentos de proteção pessoal;

- Erros humanos: erros operacionais ou de manutenção;

A aplicação da APR é realizada através de um levantamento de possíveis falhas de determinada área ou operação, através de uma equipe multidisciplinar, também pode ser feita através de uma brainstorming. 


\subsubsection{Análise quantitativa}

A análise quantitativa de riscos visa à avaliação de forma numérica da probabilidade de ocorrência dos riscos identificados e seus devidos impactos. (MELO, 2012)

\subsubsection{Análise qualitativa}

De acordo com Moraes (2013), a análise qualitativa de riscos possibilita que uma empresa possa estabelecer uma escala prioritária dos riscos inerentes ao processo, em função de sua graduação.

Dentre alguns conceitos fundamentais a análise qualitativa são eles:

- Perigo: uma ou mais condições, físicas ou químicas, com potencial para causar danos às pessoas, à propriedade, ao meio ambiente ou à combinação desses. (CETESB, 2011)

- Causas: eventos simples ou combinados. As causas podem envolver tanto as falhas intrínsecas de equipamentos, como vazamentos, rupturas e falhas de instrumentação, quanto a erros humanos de operação e manutenção. (ELETRONUCLEAR, 2014)

- Efeitos/Impactos: severidade das consequências provocadas por um determinado perigo. (AICHE, 2008)

- Modos de deteç̧ão: a deteç̧ão da ocorrência do perigo tanto pode ser realizada através de instrumentação (alarmes de pressão, de temperatura). (ELETRONUCLEAR, 2014)

- Frequência: "fornecem uma indicação qualitativa da frequência esperada de ocorrência para cada um dos cenários identificados”. (ELETRONUCLEAR, 2014)

\section{METODOLOGIA}

Quanto aos fins, pode se classificar à presente pesquisa como: Descritiva, Exploratória, Explicativa e Aplicada.

Para Gil (2010), as pesquisas descritivas têm como objetivo primordial a descrição das características de determinada população ou fenômeno ou, então, o estabelecimento de relações entre variáveis. A pesquisa é exploratória, têm como propósito proporcionar maior familiaridade com o problema, com vistas a torná-lo mais explícito ou a construir hipóteses. A pesquisa explicativa detecta os fatores que contribuem para o acontecimento de um fenômeno, tornando-o inteligível, explicando a razão dos acontecimentos. A pesquisa aplicada é gerada pela necessidade de resolução de problemas concretos, tendo finalidade prática. (VERGANA, 2009)

Quanto aos meios, pode se dizer que o presente estudo pode ser classificado como: Pesquisa de campo, Pesquisa bibliográfica e Estudo de caso.

O universo do presente estudo é a aplicação da análise preliminar de risco, na plataforma de carregamento, de uma base de distribuição de combustíveis onde todos os dados foram coletados para aplicação da APR.

\section{ESTUDO DE CASO}

\subsection{A EMPRESA}

A empresa está entre uma das maiores no segmento de distribuição de combustíveis no Brasil. Atualmente possui mais de 6.000 postos voltados a atender às necessidades diárias dos consumidores, ofertando desde combustíveis e lubrificantes até produtos de conveniência; localizada no Estado do Rio de Janeiro, atualmente a base possui uma área de 
$35.250 \mathrm{~m}^{2}$ com $14.268 \mathrm{~m}^{2}$ de área construída, com predominância na atividade de recebimento, armazenagem e distribuição de combustíveis, com processos passíveis de ocorrência de vazamentos, incêndios e explosões.

\subsection{CARACTERÍSTICAS DE OPERAÇÃO E ESTRUTURA}

Atualmente o sistema de abastecimento dos tanques é suprido pelo modal rodoviário e dutoviário, de acordo com os produtos comercializados. Sendo biodiesel exclusivamente com recebimento pelo modal rodoviário, o etanol etílico anidro e o etanol etílico hidratado com recebimento dutoviário e rodoviário vindo de usinas em SP e MG, e o diesel marítimo, gasolina com o recebimento dutoviário.

Todo o sistema de recebimento dutoviário possui identificações para cada linha de recebimento do produto, de forma evitar a contaminação no tanque devido a alguma manobra indevida, conforme apresentada Figura 1 a seguir.

Figura 1: Dutos de Recebimento de Produto

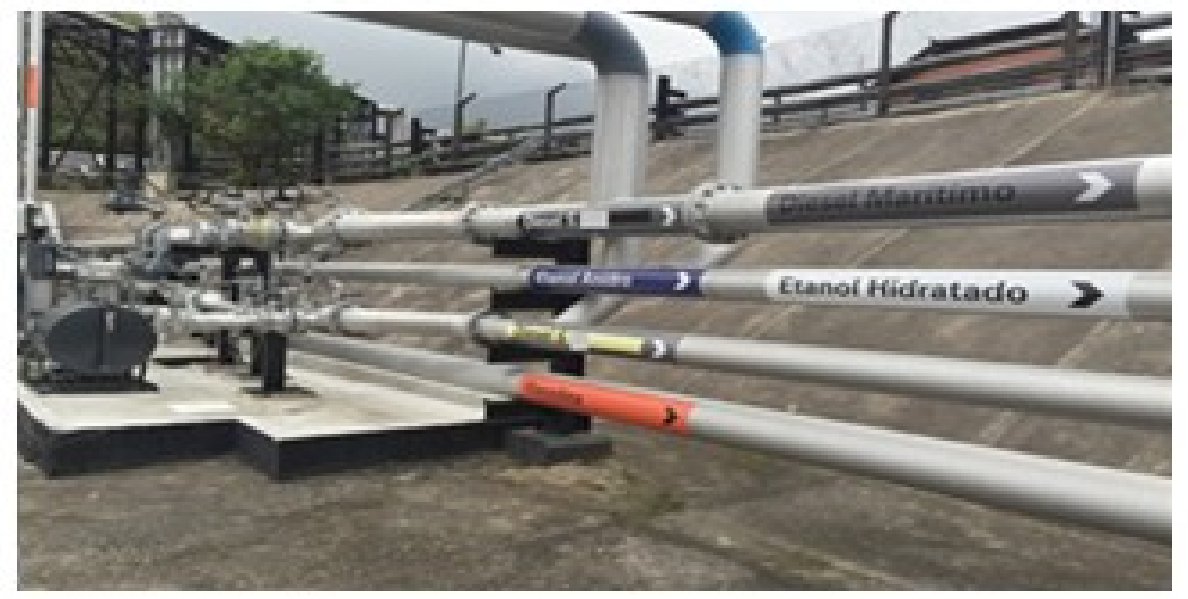

Fonte: Autores (2018)

A base possui uma capacidade de armazém de $40.505 \mathrm{~m}^{3}$, dentre os 7 tipos de produtos atualmente comercializados.

Os tanques são apoiados no solo através de uma base de concreto, estaqueada e dimensionada para esta finalidade, permitindo o escoamento de descargas atmosféricas. A chapa dos tanques é dimensionada para absorver estas descargas. Os tanques são conectados aos pontos de transferência, através de tubulações de aço, também dimensionadas para absorver descargas atmosféricas, e aterradas para dissipar esta energia.

Os tanques são instalados em bacia de contenção, dimensionada pela Norma ABNT NBR 17505-2. A bacia de tanques tem sistema de coleta de drenagem, de forma a evitar contaminação do produto diretamente no piso dela. Esta drenagem é encaminhada ao sistema de separação de água e óleo, de forma a evitar o lançamento de águas contaminadas diretamente na drenagem natural.

A plataforma de carregamento conta com 9 ilhas para a realização das atividades de carregamento, cada ilha é estruturada com 5 braços de carregamento, entretanto as disposições dos produtos variam de acordo com a característica de cada uma delas. Conforme Tabela 1 a seguir, é informada a disposição de cada produto para cada ilha de carregamento. 
Tabela 1: Configuração das ilhas de carregamentos

\begin{tabular}{lll}
\hline \multicolumn{2}{c}{ Plataforma de Carregamento } \\
\hline IItha & Quantidade braço de carregamento / produto & \\
\hline 1 & 1 Álcool; 2 Gasolina; 2 Diesel & Carregamento \\
2 & 1 Álcool; 1 Gasolina; 3 Diesel & Top loading \\
3 & 2 Gasolina; 3 Diesel & Top loading \\
4 & 2 Gasolina; 3 Diesel & Top loading \\
5 & 4 Diesel; 1 Diesel Maritimo & Bottom Loading \\
6 & 2 Gasolina; 2 Diesel; 1 Diesel Maritimo & Bottom Loading \\
7 & 1 Gasolina; 3 Diesel; 1 Diesel Maritimo & Bottom Loading \\
8 & 4 Diesel; 1 Diesel Maritimo & Bottom Loading \\
9 & 2 Gasolina; 2 Diesel; 1 Diesel Maritimo & Bottom Loading \\
\hline
\end{tabular}

Fonte: Autores (2018)

Para o abastecimento na plataforma de carregamento, existem bombas de carregamento que impulsionam os produtos desde os tanques até os braços de carregamento, de forma permitir a realização do carregamento em cada ilha.

Todas as bombas funcionam automaticamente ao entrar em operação os braços de carregamento e permissão do overfill (sistema anti-transbordo). A Tabela 2 a seguir, apresenta a vazão das bombas para cada produto.

Tabela 2: Vazão das bombas para plataforma de carregamento

\begin{tabular}{lll}
\hline Tipo de operação & Produto & Capacidade $\left(\mathbf{m}^{3} / \mathbf{h}\right)$ \\
\hline & Gasolina A & 95,0 \\
& Óleo Diesel S-10 & 112,0 \\
& Óleo Diesel S-500 & 108,0 \\
Carregamento & Óleo Diesel Marítimo & 120,0 \\
& Biodiesel & 50,0 \\
& Etanol Etílico Anidro & 64,0 \\
& Etanol Etílico Hidratado & 112,0 \\
\hline
\end{tabular}

Fonte: Autores (2018)

\subsection{APLiCAÇ̃̃o DA APR NA GESTÃo DE RISCO}

A APR tem por objetivo identificar situações perigosas, avaliar a severidade de eventuais impactos decorrentes desses perigos e fornecer subsídios necessários para permitir a implementação de medidas mitigadoras para a redução e controle dos riscos.

Para aplicação da APR, foram executadas as seguintes tarefas:

\subsubsection{Definição das fronteiras das instalações analisadas}

A definição de fronteira determinada foi à plataforma de carregamento, em virtude da grande rotatividade de motoristas e caminhões, o que torna ainda mais complexo o local em estudo.

Atualmente a base recebe em média 300 caminhões/dia, para as atividades de carregamento, onde $90 \%$ deste volume são referentes à frota terceirizada.

\subsubsection{Coleta de informações sobre as instalações e as características das substâncias perigosas envolvidas}

A coleta das informações supracitadas foi feita diretamente no campo, em conjunto com os operadores e supervisores, os quais exercem atividades diariamente no local em estudo. Reunir todos os envolvidos foi importante devido a diferentes percepções de níveis gerenciais e operacionais, que de fato contribuíram para a análise. 


\subsubsection{Definição dos módulos de análise}

Os módulos de análises adotados para estudo dentro da plataforma de carregamento foram levados em consideração com base nas ilhas de carregamentos que atualmente tem o maior volume carregado diariamente para cada tipo de carregamento, ou seja, bottom loading e top loading.

\subsubsection{Aplicação da APR}

O escopo da APR abrange todos os eventos perigosos cujas causas tenham origem na instalação analisada, englobando tanto as falhas intrínsecas de componentes ou sistemas, como eventuais erros operacionais (erros humanos), principalmente aqueles decorrentes de falhas nos procedimentos ou na execução deles.

Foram excluídos da análise os eventos perigosos causados por agentes externos, tais como: terremotos e inundações.

O formulário contém 9 colunas, as quais são preenchidas conforme a descrição apresentada abaixo:

1. Perigo: Esta coluna contém os perigos identificados para o módulo de análise em estudo. Os perigos são eventos acidentais que têm potencial para causar danos às instalações, aos operadores, ao público ou ao meio ambiente.

2. Causas: As causas genéricas de cada perigo são discriminadas nesta coluna. Estas causas envolvem tanto falhas intrínsecas de equipamentos (vazamentos, rupturas, falhas de instrumentação etc.) como erros humanos de operação e manutenção.

3. Salvaguardas existentes: Nesta coluna são relacionados os recursos e sistemas disponíveis na instalação que permitem a detecção dos perigos e/ou mitigação dos potenciais riscos ocasionados pelos desvios e causas identificadas.

4. Efeitos: Os possíveis efeitos danosos de acidentes envolvendo produtos perigosos serão divididos em quatro categorias conforme matriz de risco utilizada: Integridade Pessoal (funcionários, contratados e público externo); Meio ambiente e Imagem da Companhia.

A adoção desta descrição para os efeitos tem como objetivo facilitar o julgamento das frequências e severidades associadas a estes efeitos.

5. Categoria de Frequência: No âmbito desta APR, um cenário de acidente é definido como o conjunto formado pelo perigo identificado, suas causas e cada um dos seus efeitos.

De acordo com a metodologia de APR adotada, os cenários de acidente são classificados qualitativamente em categorias de frequência conforme critério apresentado na Tabela 3 a seguir:

Tabela 3: Categorias de frequência

\begin{tabular}{|c|c|c|}
\hline Categoria & Frequência Anual & Descriçà̀o \\
\hline Frequente & $F>10-1$ & Esperado ocorrer muitas vezes durante a vida útil da instalação \\
\hline Provável & $10-2<\mathrm{f}<10-1$ & Esperado ocorrer mais de uma vez durante a vida útil da instalação \\
\hline Ocasional & $10-3<\mathrm{f}<10-2$ & Possivel de ocorrer até uma vez durante a vida útil da instalação \\
\hline Remoto & $10-4<f<10-3$ & $\begin{array}{l}\text { Não esperado ocorrer durante a vida útil da instalação, apesar de } \\
\text { haver referências }\end{array}$ \\
\hline Improvável & $\mathrm{F}<10-4$ & $\begin{array}{l}\text { Conceitualmente possivel, mas extremamente improvável de } \\
\text { ocorrer durante a vida útil da instalação. Năo há referências } \\
\text { históricas de que isto tenha ocorrido }\end{array}$ \\
\hline
\end{tabular}

Fonte: Autores (2018) 
6. Categoria de Severidade: De acordo com a ferramenta APR adotada, os cenários de acidente são classificados em categorias de severidade, as quais fornecem uma indicação qualitativa do grau de severidade das consequências dos cenários identificados. As categorias de severidade são classificadas conforme critério apresentado na Tabela 4 a seguir.

Tabela 4: Categorias de severidade

\begin{tabular}{|c|c|c|c|c|}
\hline $\begin{array}{l}\text { Categoria } \\
\text { de Severidade }\end{array}$ & Segurança Pessoal & Patrimônio & Meio Ambiente & Imagem \\
\hline Desprezivel & $\begin{array}{l}\text { Sem lesões, ou no máximo } \\
\text { casos de primeiros } \\
\text { socorros, sem afastamento }\end{array}$ & $\begin{array}{l}\text { Danos leves aos sistemas } \\
\text { sem comprometimento da } \\
\text { continuidade operacional da } \\
\text { instalação industrial }\end{array}$ & $\begin{array}{l}\text { Sem danos ou com } \\
\text { danos } \\
\text { insignificantes }\end{array}$ & Sem impacto \\
\hline Marginal & $\begin{array}{lrrr}\text { Lesōes } & \text { leves } & \text { em } \\
\text { empregados } & \text { e } & \text { terceiros. } \\
\text { Ausência } & \text { de } & \text { lesões } \\
\text { extramuros } & & & \end{array}$ & $\begin{array}{l}\text { Danos leves aos sistemas } \\
\text { com comprometimento da } \\
\text { continuidade operacional da } \\
\text { instalação industrial }\end{array}$ & Danos leves & Impacto local \\
\hline Critica & $\begin{array}{l}\text { Lesões de gravidade } \\
\text { moderada em pessoas } \\
\text { intramuros, lesões leves em } \\
\text { pessoas extramuros }\end{array}$ & $\begin{array}{l}\text { Danos severos a sistemas da } \\
\text { instalação } \\
\text { (reparação lenta) }\end{array}$ & $\begin{array}{l}\text { Danos severos com } \\
\text { efeito localizado }\end{array}$ & Impacto regional \\
\hline Catastrófica & $\begin{array}{l}\text { Provoca morte ou lesões } \\
\text { graves em } 1 \text { ou mais intra } \\
\text { ou extramuros }\end{array}$ & Perda da instalação industrial & $\begin{array}{l}\text { Danos severos em } \\
\text { áreas sensiveis ou se } \\
\text { estendendo para } \\
\text { outros locais }\end{array}$ & $\begin{array}{l}\text { Impacto nacional } \\
\text { e ou Internacional }\end{array}$ \\
\hline
\end{tabular}

Fonte: Autores (2018)

7. Categoria de Risco: Combinando-se as categorias de frequência com as de severidade obtém-se o risco do cenário analisado, conforme matriz de risco apresentada na Tabela 5 a seguir.

Tabela 5: Matriz de Risco

\begin{tabular}{|c|c|c|c|c|c|c|}
\hline \multirow{2}{*}{\multicolumn{2}{|c|}{$\begin{array}{c}\text { Matriz de } \\
\text { Aceitabilidade } \\
\text { de Risco }\end{array}$}} & \multicolumn{5}{|c|}{ FREQUENCLA } \\
\hline & & $\begin{array}{l}\text { Improvável } \\
\text { (Im) }\end{array}$ & Remoto (Re) & Ocasional (Oc) & Provável (Pr) & Frequente (Fr) \\
\hline \multirow{4}{*}{ 唩 } & $\begin{array}{c}\text { Catastrófica } \\
\text { (0) }\end{array}$ & $\begin{array}{c}\text { Médio } \\
\text { Obrigatório } \\
\text { Recomendações } \\
\text { Confirmar } \\
\text { Riscos com } \\
\text { estudo } \\
\text { complementar }\end{array}$ & $\begin{array}{c}\text { Médio } \\
\text { Obrigatório } \\
\text { Recomendações } \\
\text { Confirmar } \\
\text { Riscos com } \\
\text { estudo } \\
\text { complementar }\end{array}$ & $\begin{array}{l}\text { Näo Aceitível } \\
\text { Obrigatório } \\
\text { Recomendaçoóes } \\
\text { Confirmar } \\
\text { Riscos com } \\
\text { estudo } \\
\text { complementar }\end{array}$ & $\begin{array}{l}\text { Näo Aceitível } \\
\text { Obrigatório } \\
\text { Recomendaçōes } \\
\text { Confirmar } \\
\text { Riscos com } \\
\text { estudo } \\
\text { complementar }\end{array}$ & $\begin{array}{l}\text { Não Aceitível } \\
\text { Obrigatório } \\
\text { Recomendaçöes } \\
\text { Confirmar } \\
\text { Riscos com } \\
\text { estudo } \\
\text { complementar }\end{array}$ \\
\hline & $\begin{array}{l}\text { Crítico } \\
\text { (1) }\end{array}$ & $\begin{array}{c}\text { Médio } \\
\text { Obrigatório } \\
\text { Recomendaçăes } \\
\text { Confirmar } \\
\text { Riscos com } \\
\text { estudo } \\
\text { complementar }\end{array}$ & $\begin{array}{c}\text { Médio } \\
\text { Obrigatório } \\
\text { Recomendaçães } \\
\text { Confirmar } \\
\text { Riscos com } \\
\text { estudo } \\
\text { complementar }\end{array}$ & $\begin{array}{c}\text { Médio } \\
\text { Obrigatório } \\
\text { Recomendaçð̄es } \\
\text { Confirmar } \\
\text { Riscos com } \\
\text { estudo } \\
\text { complementar }\end{array}$ & $\begin{array}{l}\text { Não Aceitivivel } \\
\text { Obrigatório } \\
\text { Recomendaçбes } \\
\text { Confirmar } \\
\text { Riscos com } \\
\text { estudo } \\
\text { complementar }\end{array}$ & $\begin{array}{l}\text { Não Aceittível } \\
\text { Obrigatório } \\
\text { Recomendaçס̄es } \\
\text { Confirmar } \\
\text { Riscos com } \\
\text { estudo } \\
\text { complementar }\end{array}$ \\
\hline & $\begin{array}{l}\text { Moderada } \\
\text { (2) }\end{array}$ & Aceitável & Aceitável & Aceitável & $\begin{array}{c}\text { Médio } \\
\text { Obrigatório } \\
\text { Recomendaçōes }\end{array}$ & $\begin{array}{l}\text { Não Aceittível } \\
\text { Obrigatório } \\
\text { Recomendações } \\
\text { Confirmar } \\
\text { Riscos com } \\
\text { estudo } \\
\text { complementar }\end{array}$ \\
\hline & $\begin{array}{c}\text { Baixa } \\
\text { (3) }\end{array}$ & Aceitável & Aceitável & Aceitável & Aceitável & $\begin{array}{c}\text { Médio } \\
\text { Obrigatório } \\
\text { Recomendaçōes }\end{array}$ \\
\hline
\end{tabular}

Fonte: Autores (2018)

8. Recomendações/Sugestões: Esta coluna contém as recomendações de medidas mitigadoras de risco propostas pela equipe do estudo de risco ou observações visando esclarecer o entendimento da análise do cenário.

9. Identificador do Cenário de Acidente: Esta coluna contém um número de identificação do cenário de acidente, sendo preenchida sequencialmente para facilitar a consulta a qualquer cenário de interesse. 
No primeiro módulo definido - Ilha de carregamento 2 (plataforma top loading) foi caracterizada como o primeiro cenário o perigo com o pequeno vazamento de líquido inflamável, as causas levantadas para o evento foram: Furo/fissura linha, junta, flange, abertura indevida de drenos, falha operacional, falha em equipamentos/acessórios, avaria do caminhão, colisão, transbordamento e falha na vedação da válvula de fundo. Como salvaguardas existentes: Área contida impermeabilizada (ilha de carregamento), procedimento operacional de carregamento, treinamento de motorista para operação de carregamento e movimentação de caminhão dentro da base, checklist de verificação em caminhões, botoeira de parada de emergência (ilha de carregamento), sistema fixo de combate a incêndio, mediterra, plano de controle de Emergência (PCE). Na Tabela 6 a seguir é apresentado a APR do primeiro cenário para o perigo com pequeno vazamento.

Tabela 6: APR do primeiro cenário para pequeno vazamento

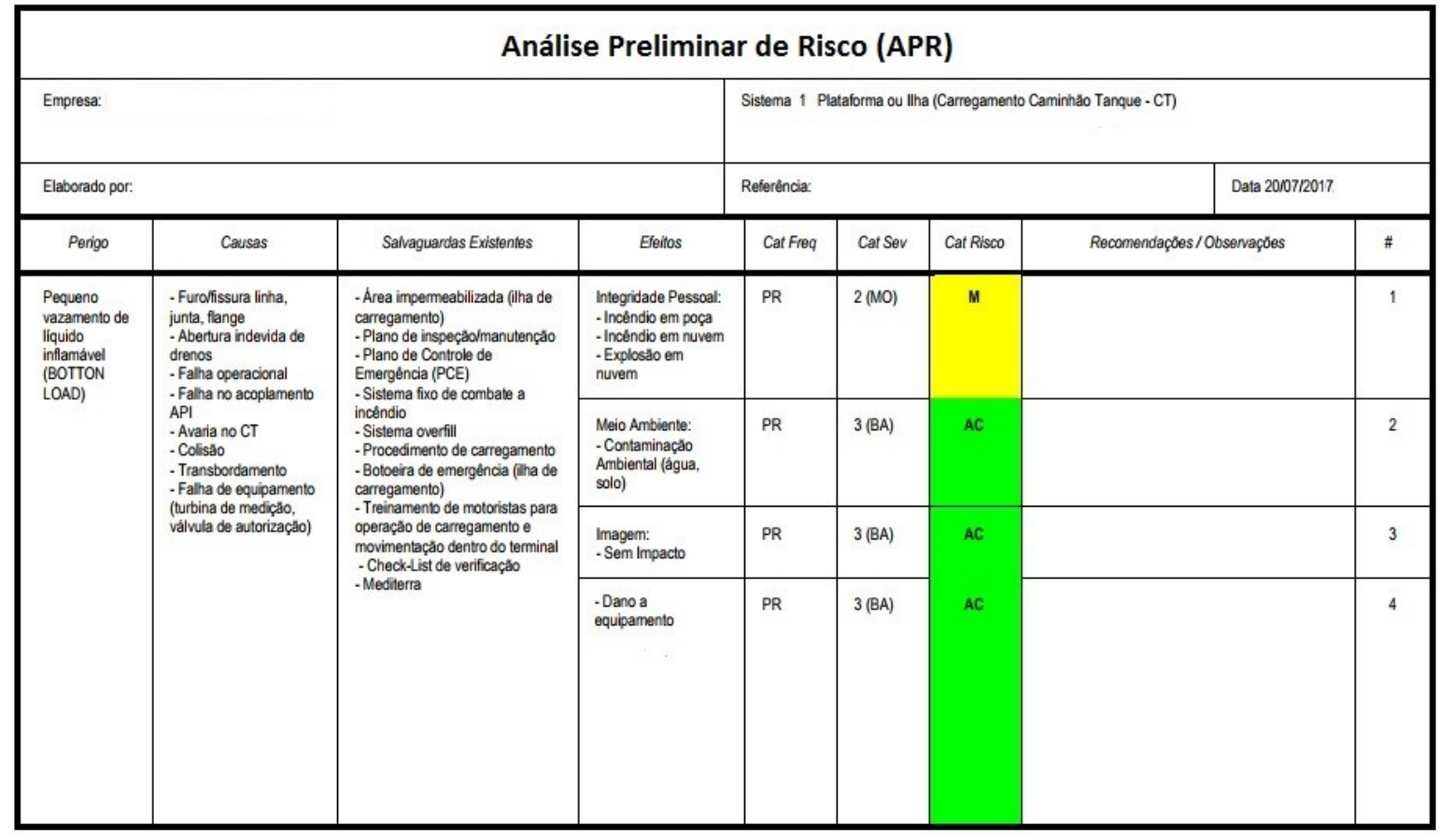

Fonte: Autores (2018)

Os efeitos em relação à integridade pessoal foram: Incêndio em poça, incêndio em nuvem, explosão em nuvem, com a categoria definida como previsível, categoria de severidade moderada (2) e risco médio, nesta primeira análise de efeito foi recomendado à instalação do sistema overfill no carregamento. Em relação os efeitos no meio ambiente foram levados em consideração à contaminação da água e solo, com categoria de frequência previsível e categoria de severidade baixa (3), com risco aceitável. Os efeitos a imagem da empresa, foi considerado sem impacto, em virtude da proporção do perigo, com categoria de frequência previsível, categoria de severidade baixa (3) e risco aceitável, por fim os efeitos referentes ao patrimônio da empresa foram levados em consideração o dano ao equipamento, com categoria de frequência previsível, categoria de severidade baixa (3) e risco aceitável.

Ainda no primeiro módulo de análise, foi realizada uma perspectiva para o segundo perigo, com grande vazamento de líquido inflamável, as principais causas apontadas foram: Ruptura da linha/flange/junta, impacto mecânico considerando que o motorista arranque com o caminhão com o braço de carregamento ainda acoplado ao caminhão, falha operacional, falha em equipamentos e acessórios, avaria no caminhão, transbordamento. As salvaguardas existentes foram às mesmas consideradas com o perigo de pequeno vazamento, não tivemos 
alteração, pois os recursos são os mesmos. Os efeitos relacionados à integridade pessoal, também se mantiveram iguais ao primeiro evento, tivemos alteração na categoria de frequência, em virtude de o evento ter sido considerado ocasional, com a categoria de severidade crítica (1), e risco médio. Em relação dos efeitos ao meio ambiente foi considerada a contaminação do solo, água e ar, com a categoria de frequência ocasional, categoria de severidade moderada (2) e risco aceitável. Em razão da proporção do vazamento em análise, os efeitos relacionados à imagem da empresa foram regionais, com a categoria de frequência ocasional e severidade moderada (2), com risco aceitável. Os efeitos ao patrimônio da empresa foram danos aos equipamentos e perda de produto, com categoria de frequência ocasional e severidade moderada (2), com risco aceitável. Na Tabela 7 a seguir é apresentado a APR do primeiro cenário para o perigo com grande vazamento.

Tabela 7: APR do primeiro cenário para grande vazamento

\begin{tabular}{|c|c|c|c|c|c|c|c|c|}
\hline \multicolumn{9}{|c|}{ Análise Preliminar de Risco (APR) } \\
\hline \multicolumn{4}{|l|}{ Empresa: } & \multicolumn{5}{|c|}{ Sistema 1 Plateforma ou llha (Carregamento Caminhto Tanque - CT) } \\
\hline \multicolumn{4}{|l|}{ Elaborado por: } & \multicolumn{3}{|l|}{ Referetenciax } & & Data 200712017. \\
\hline Penigo & Causas & Salvaguardas Existentes & Eteilos & Cat Freq & Cat Sev & Cat Risco & Recomendapcos/Obsenvapbes & \# \\
\hline \multirow[t]{4}{*}{$\begin{array}{l}\text { Grande } \\
\text { vazamento de } \\
\text { liquido } \\
\text { infanável } \\
\text { (BOTTON } \\
\text { LOAD) }\end{array}$} & \multirow{4}{*}{ 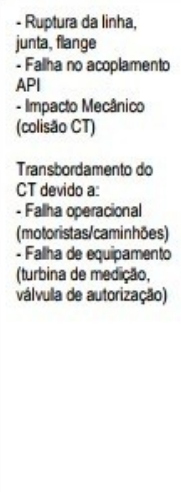 } & \multirow{4}{*}{ 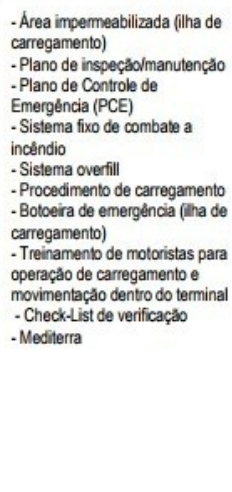 } & $\begin{array}{l}\text { IItegidade Pessoal: } \\
\text { Incendio em poça } \\
\text { Incendio em nuvem } \\
\text { Explosto em nuvem } \\
\text { Jato de fogo }\end{array}$ & oc & 1 (CR) & M & 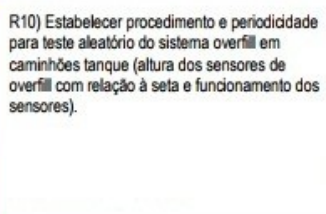 & 5 \\
\hline & & & $\begin{array}{l}\text { Meio Anbiente: } \\
\text { Contaminaçao } \\
\text { ambieintal (solo, } \\
\text { aguua) }\end{array}$ & oc & 2 (MO) & AC & & 6 \\
\hline & & & $\begin{array}{l}\text { Imagem: } \\
\text {-Regional }\end{array}$ & $o c$ & 2 (MO) & $\mathrm{AC}$ & & 7 \\
\hline & & & $\begin{array}{l}\text {-Danos a } \\
\text { equipamentiose } \\
\text { perda de produto }\end{array}$ & oc & 2 (MO) & $\mathrm{AC}$ & & 8 \\
\hline
\end{tabular}

Fonte: Autores (2018)

Para o segundo módulo de análise na Ilha de carregamento 3 - (plataforma bottom loading), também foram considerados perigos com pequeno e grande vazamento de produtos inflamáveis. Na primeira análise com perigo de pequeno vazamento as principais causas foram: furo/fissura na linha, abertura indevida de drenos, falha operacional, falha no acoplamento, avaria no ct, colisão, transbordamento e falha de equipamento. Entre as salvaguardas existentes temos como diferença apenas o sistema overfill. Os efeitos relacionados à integridade pessoal foram: incêndio em poça, incêndio em nuvem, explosão em nuvem, com a categoria de frequência previsível e severidade moderada (2), com risco médio. Em relação ao meio ambiente foi considerada contaminação ambiental na água e solo, com categoria de frequência previsível e severidade baixa (3), com risco médio. No que tange a imagem da empresa, foi considerado sem impacto, categoria de frequência previsível e severidade baixa (3), com risco aceitável. Em relação ao patrimônio, os efeitos foram apenas em dano ao equipamento, com a frequência previsível e severidade baixa (3), com risco aceitável. Na Tabela 8 a seguir é apresentado a APR do segundo cenário para o perigo com pequeno vazamento. 
Tabela 8: APR do segundo cenário para pequeno vazamento

\begin{tabular}{|c|c|c|c|c|c|c|c|c|}
\hline \multicolumn{9}{|c|}{ Análise Preliminar de Risco (APR) } \\
\hline \multicolumn{4}{|l|}{ Empress: } & \multicolumn{5}{|c|}{ Sistema 2 , Plataforma ou llha (Carregamento Caminhä Tanque - CT) } \\
\hline \multicolumn{4}{|l|}{ Elaborado por: } & \multicolumn{3}{|l|}{ Referetendix } & \multicolumn{2}{|c|}{ Data 200712017. } \\
\hline Penigo & Causas & Salvaguardas Existentes & Etertos & Cat freq & Cat Sev & Cat Risco & Recomendaçbes/Obsenaçbes & $\#$ \\
\hline \multirow[t]{4}{*}{ 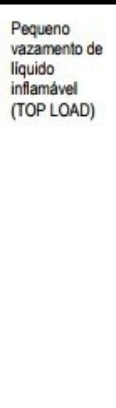 } & \multirow{4}{*}{ 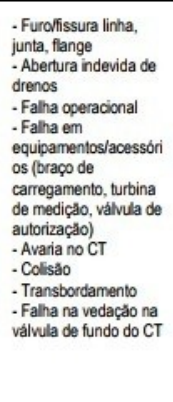 } & \multirow{4}{*}{ 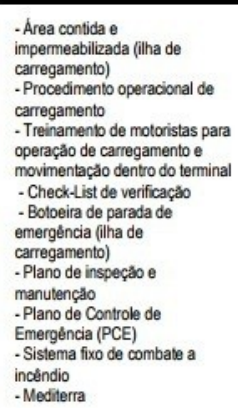 } & 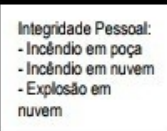 & PR & 2 (MO) & M & $\begin{array}{l}\text { R12) Instalar sistema overfil no carregamento } \\
\text { top laad. }\end{array}$ & 13 \\
\hline & & & $\begin{array}{l}\text { Meio Ambiente: } \\
\text {-Contaminaçá } \\
\text { Ambieintal (agua, } \\
\text { solo) }\end{array}$ & PR & $3(\mathrm{BA})$ & $A C$ & & 14 \\
\hline & & & $\begin{array}{l}\text { Imagem: } \\
\text {-Sem Impacto }\end{array}$ & PR & $3(B A)$ & $\mathrm{AC}$ & & 15 \\
\hline & & & $\begin{array}{l}\text { - Danoa a } \\
\text { equipamentio }\end{array}$ & PR & $3(\mathrm{BA})$ & AC & & 16 \\
\hline & & & & & & & & \\
\hline & & & & & & & & \\
\hline
\end{tabular}

Fonte: Autores (2018)

No segundo módulo, foi avaliado o cenário para o perigo com grande vazamento de inflamáveis, foram considerados como principais causas ruptura da linha, falha no acoplamento, impacto mecânico (colisão de ct), transbordamento, falha operacional, falha de equipamento. Dentre as salvaguardas existentes não ocorrem alterações. Os efeitos relacionados à integridade pessoal foram: incêndio em poça, incêndio em nuvem, explosão em nuvem e jato de fogo, com a categoria de frequência ocasional, categoria de severidade crítica (1), com risco médio. As recomendações para este efeito foi estabelecer procedimento de periodicidade para teste aleatório do sistema overfill em caminhões tanque em relação à altura dos sensores de overfill e a seta de funcionamento. Os efeitos ao meio ambiente foram os mesmos em virtude do carregamento bottom loading, com a categoria de frequência ocasional, severidade moderada (2) e risco aceitável. No quesito imagem da empresa, foram considerados com impacto regional, categoria de frequência ocasional, severidade moderada (2) e risco aceitável. Por fim os efeitos referentes ao patrimônio foram considerados, a perda de produto e danos aos equipamentos, com categoria de frequência ocasional, severidade moderada (2) e risco aceitável. Na Tabela 9 a seguir é apresentado a APR do primeiro cenário para o perigo com grande vazamento. 
Tabela 9: APR do segundo cenário para grande vazamento

\begin{tabular}{|c|c|c|c|c|c|c|c|c|}
\hline \multicolumn{9}{|c|}{ Análise Preliminar de Risco (APR) } \\
\hline \multicolumn{4}{|l|}{ Empresa: } & \multicolumn{5}{|c|}{ Sistema 2 Plataforma ou llha (Caregamento Caminhao Tanque - CT) } \\
\hline \multicolumn{4}{|l|}{ Elaborado por: } & \multicolumn{3}{|l|}{ Referencicia } & & Data 2000712017. \\
\hline Perigo & Causas & Salvaguardas Existentes & Eteinos & Cat Freq & Cat Sev & Cat Risco & Recomendachos / Observaços & \# \\
\hline \multirow[t]{4}{*}{$\begin{array}{l}\text { Grande } \\
\text { vazamento de } \\
\text { liquido } \\
\text { infanável } \\
\text { (TOP LOAD) }\end{array}$} & \multirow{4}{*}{ 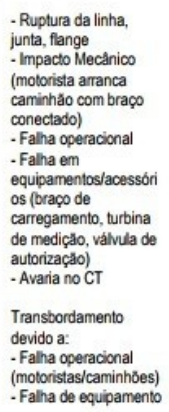 } & \multirow{4}{*}{ 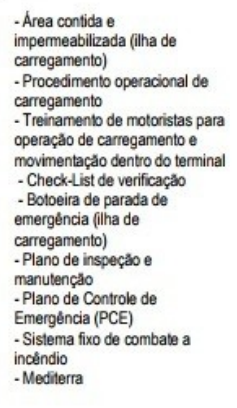 } & 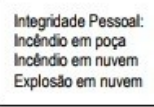 & $o c$ & 1 (CR) & M & $\begin{array}{l}\text { R12) Intstalar sistema overfil no carregamento } \\
\text { top load. }\end{array}$ & 17 \\
\hline & & & $\begin{array}{l}\text { Meio Ambiente: } \\
\text { Contaminaçdo } \\
\text { ambieintal (solo, } \\
\text { aggua, ar) }\end{array}$ & oc & 2 (MO) & $A C$ & & 18 \\
\hline & & & $\begin{array}{l}\text { Imagem: } \\
\text {-Regional }\end{array}$ & oc & 2 (MO) & AC & & 19 \\
\hline & & & $\begin{array}{l}\text {-Danos a } \\
\text { equipamentiose } \\
\text { percida de procoutio }\end{array}$ & oc & 2 (MO) & $\mathrm{AC}$ & & 20 \\
\hline
\end{tabular}

Fonte: Autores (2018)

\section{CONSIDERAÇÕES FINAIS}

Com base na proposta do presente estudo, foi possível avaliar os riscos do funcionamento das operações de carregamento dentro da base de distribuição de combustíveis. Durante o estudo foi analisados um total de dois sistemas, sendo proposto pela equipe multidisciplinar, de um total de cinco recomendações.

Em relação à classificação dos resultados, com base na combinação da matriz de risco, foi encontrado um total de 30 riscos aceitáveis e 6 cenários com risco médio.

A boa gestão na implementação das recomendações sugeridas, contribuiu principalmente no aumento do nível de segurança para as pessoas, na qualidade do produto e na manutenção da operacionalidade e disponibilidade dos sistemas que compõem os sistemas avaliados neste estudo.

Ficou evidenciado que para ter sucesso na redução de riscos e no combate a possíveis sinistros é necessário que tenha uma conscientização de toda equipe de funcionários e prestadores de serviço, de modo que ocorra uma sinergia de prevenção de acidentes diariamente.

\section{REFERÊNCIAS BIBLIOGRÁFICAS}

A. C. GIL. Como Elaborar Projetos de Pesquisa. 5a ed. São Paulo: Atlas, 2010.

AGÊNCIA NACIONAL DO PETRÓLEO. Anuário Estatístico Brasileiro do Petróleo e do Gás Natural e Biocombustíveis. Agência Nacional do Petróleo. Rio de Janeiro, 2016.

AICHE. American Institute for Chemical Engineers. Guidelines for Hazard Evaluations Third Edition, 2008. New York, New York.

CETESB - Norma P4.261- Risco de Acidente de Origem Tecnológica - Método para decisão e termos de referência. São Paulo, 2011. 
E. CALIXTO. Uma metodologia para gerenciamento de risco em empreendimentos: Um estudo de caso na Indústria de petróleo. Anais do XXVI Encontro Nacional de Engenharia de Produção - XXVI ENEGEP, Fortaleza, 2006. Disponível em: http://www.abepro.org.br/biblioteca/enegep2006_tr500338_8619.pdf. Acesso em: 12 mar. 2018.

E. L. de Amorim. Apostila de Ferramentas de Análise de Risco. UNIFAL, Alagoas, 2010. Disponível em: https://sites.google.com/site/elcaufal/disciplinas/programacao-estruturada. Acesso em: 02 abr. 2018.

ELETRONUCLEAR. Estudo de Impacto Ambiental - EIA da Unidade 3 da Central Nuclear Almirante Álvaro Alberto - Análise e Gerenciamento de Risco e de Emergência, cap. 12.2.7.2, Volume 6, 2014.

F. de CICCO, e M. L. FANTAZINNI. Introdução à engenharia de segurança de sistema. $2^{a}$ edição. São Paulo, FUNDACENTRO, 1982.

G. MORAES. Sistema de gestão de riscos: estudos de análise de riscos offshore e onshore. Rio de Janeiro: Gerenciamento Verde Editora, 2013.

G. Ribas. Modelo de programação estocástica para o planejamento estratégico da cadeia integrada de petróleo. Dissertação (Mestrado). Pontifícia Universidade Católica do Rio de Janeiro. Rio de Janeiro, 2008. Disponível em: http://www.lambda.maxwell.ele.pucrio.br/12291/12291_1.PDF. Acesso em: 06 abr. 2018.

M. MELO. Guia de Estudo para o Exame PMP: Project Management Professional Exam. 4 ed., Rio de Janeiro: Brasport, 2012.

SINDICOM, Anuário Estatístico Sindicato nacional das empresas distribuidoras de combustíveis e lubrificantes. pag.12, 62, Editora Trena. Rio de Janeiro, 2016.

S. C. Vergara. Projetos e Relatórios de Pesquisa em Administração. 11 ed. São Paulo: Editora Atlas, 2009.

SISTEMA DE GESTÃO VOTORANTIM. Manual do Observador. 1 ed. Juiz de Fora: VOTORANTIM METAIS, 2005. 